\title{
A Discrete-Event Simulation Approach to Assess the Benefits of Parking Technologies in Hospitals
}

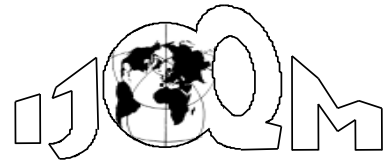

DOI: $10.46970 / 2021.27 .2 .4$

Volume 27, Number 2

June 2021, pp. 141-152
Milton Soto-Ferrari

Indiana StateUniversity

(milton.soto-ferrari@indstate.edu)

Daniel Romero-Rodriguez

Juan P. Escorcia-Caballero

Universidad del Norte

(hromero@uninorte.edu.co)

(juane@uninorte.edu.co)

Julio-Mario Daza-Escorcia

Fundación Universidad de América

(julio.daza@profesores.uamerica.edu.co)

Odette Chams-Anturi

Universidad de la Costa

(ochams@cuc.edu.co)

As essential service providers, hospitals receive a large quantity of traffic every day. The deficiency in hospital parking facilities causes drivers to spend more time getting a parking spot, causing delays for patients and physicians. We develop and validate discrete-event simulation models upon other parking configurations in a Saudi Arabian hospital to assess smart parking benefits. We find that technology implementations are not advantageous for condensed parking areas. Our results indicate that the improvements in drivers' time will depend on the various factors of the parking configuration and aspects such as the car arrival rate, car flow, and parking visibility.

Keywords: Smart Parking Technology, Simulation, Hospital Facilities, Parking Configuration

\section{Introduction}

The current increase in hospital traffic congestions plays a critical role in delivering timely, safe, and high-quality healthcare for patients (Guo et al., 2018). As essential service providers, hospitals receive a large quantity of traffic every day, but they have limited parking spaces that hold back the continuous and adequate hospital user traffic. Developing traffic parking systems becomes indispensable for hospital service delivery and customer satisfaction (Alfadhlani and Afrinaldi, 2019; Chen et al., 2017). In some cases, due to the absence of adequate parking facilities, hospital users park their vehicles in unauthorized places, leading to obstruction of roads or buildings (Ali and Hassan, 2019; Zhu, 2018).

The deficiency in hospital parking facilities causes drivers to spend more time gettinga parking spot. These delays can lead to patients not arriving on time for a medical appointment or medical staff users not reaching an urgent assignment on time (Suthanaya, 2017). Literature shows that by improving the assignation of parking spaces in hospitals, delays do decrease. Smart parking systems (SPS) are technology 
solutions working through integrated software that focuses on enhancing parking flow and reducing traffic congestions(Grazioli et al., 2013). Features of SPS include vacant parking space detection, detection of improper parking, display of available parking spaces, and directional indicators toward empty parking spaces, payment facilities, and other parking spaces (e.g., vacant, occupied, reserved, and handicapped).

Eventually, when using SPS, decisions about where to park are either based on a heuristic arrangement or, in some other cases, by implementing techniques such as optimization or simulation(Geng and Cassandras, 2012; Giuffre et al., 2012). The SPS's success depends on managing the information that feeds the system through the various technologies. Information such as the total number of spaces available, number of aisles, and details such as calculating a vehicle size to analyze the space it occupies, are inputs for designing an adequate parking management strategy (Alam et al., 2018; Grazioli et al., 2013; Kotb et al., 2017).

This research seeks to evaluateSPSbenefitson other parking lots by analyzing whether its operation is appropriate in an existing hospital facility. We consider two parking configurations; a building parking lot structure with three aisles and one hundred and fifty parking spaces and an open space parking lot with two halls and forty parking spaces. We analyzed actual hospital parking data from a medical center located in Saudi Arabia to develop computer-generated discrete simulation models for each configuration. We proceeded to study the models'performance with and without the SPS assistance employing statistical hypothesis tests that evaluate whether there is a significant improvement in traffic flow when using SPS in each configuration. Our study focuses on reducing the time spent by hospital users when searching for parking spaces. While other studies emphasize the benefits of the SPS implementation, our purpose is to evaluate when it is suitable to embrace it. Furthermore, we determineda novel approach for assessing parking management strategies when SPS technologies are in consideration.

This paper is structured as follows: section two discusses the literature about SPS's hospital parking policies and technologies. Section three defines the inputs and the simulation model structure. Section four presents the computational results of the application. Section five discusses the convenience of implementing SPS technologies, and section six concludes the article.

\subsection{Smart Parking Systems (SPS)}

\section{Literature Review}

SPS functions through information and communications technologies (ICT), which helps end-users find available parking spaces with minimal time and fuel expenditure(Grazioli et al., 2013). ICT technologies include the processes of search, selection, and allocation of available parking. Several studies have reported solutions related to parking management with SPS (Giuffre et al., 2012; Klappenecker et al., 2014; Lan and Shih, 2014; Prasad et al., 2013; Teodorovic and Lucic, 2006; Xu et al., 2013). Research in these topics has been categorized mainly into space availability technology and the analysis of parking places demand and allocation. The following sections show the current investigations for each category.

\subsubsection{Space Availability Technology}

In the context of SPS, solutions such as mobile apps, RFID, sensors, and video 
technology detect information about parking spaces, vehicle types, and current occupation. RFID technology uses radio frequencies to collect information about parking spaces available where information updates in real-time via a local intranet accessed and tracked by parking users (Ganesan and Vignesh, 2007). Fiber sensors detect the rooms available in a lot. In parking solutions, the Fiber Bragg Grating sensor (FBG) embeds in the ground located to where parked vehicles' rear wheels would be in each grid's parking space. The sensor updates real-time space availability in local servers, generating notifications of occupancy to the user throughout the parking lot (Prasad et al., 2013). Video technology implements a detection and pattern recognition system to determine occupancy based on visual characteristics drawn from parking locations (Jermsurawong et al., 2014).

Further technology is the gyroscope system that sees the movement pattern to estimate the user's travel mode, car or walking, in a parking area (Xu et al. 2013; Lan and Shih 2014). Some studies, including Haoui et al. (2008), Caicedo (2009), and Jermsurawong et al. (2014), proposed a combination of underground and overhead sensors to estimate space occupancy in the parking area with a solution denominated PARC system (Parking Access and Revenue Control).In this solution, the sensors are not located in each space but rather in strategic locations. This approach allows the parking lot to be distributed into smaller areas to facilitate occupation analysis measurement.

\subsubsection{Analysis of the Demand and Allocation of Parking Places}

The information gathered with the different space availability technologies enables allocating and searching for parking spaces in an optimal or quasi-optimal approach. Various modeling approaches had been developed in the literature and are for more cases guided by mathematical modeling and simulation. For instance, Caicedo (2010) developed a demand allocation model to evaluate the benefit of manipulating information, aiming to reduce users' time spent searching for parking spaces, including the walking distances involved. Similarly, Giuffre et al. (2012) estimated the utilization level (i.e., occupancy rate) of a parking strategy. In this study, the parking spot's total walking distance to the final destination is incorporated into a mathematical model to calculate the parking lot's occupancy rate. Horng et al. (2012) proposed an adaptive recommendation mechanism for intelligent parking that adopts the user's current location to calculate the parking space closest to his position and determines when vehicles should turn to reduce road congestion and thus improve the search for a parking spot. Drivers receive the recommended parking space via text message to their cellphones. This approach proved to reduce traffic congestion and time to find an available location for parking users.

\subsection{Hospital Parking Users}

Hospital parking users have different necessities. In a hospital environment, parking users classify into four other groups; medical staff, emergency patients, outpatients, and visitors. Medical staff parking demand is rigid. Their entrances and exits are predominantly regular, and for most cases, parking spaces are assigned or reserved. Emergency patients prefer a shorter walking distance due to the urgency. Emergency patients have high volatility and uncertainty regarding patient arrivals and lengths of stay (Schäfer et al., 2019). Outpatients and visiting groups pay special attention to the 
parking fee and accept a longer walking distance (Chen et al., 2017). Standard practice for outpatients is the denominated appointment overbooking that hospitals have regularly adopted to mitigate patients' no-shows and the adverse effects of unattended medical staff time slots(Kuo et al., 2020). This multi booking strategy aims to increase hospital competitiveness (Chams-Anturi et al., 2020).Although typical, this practice affects the parking area's efficiency since it alters the number of spaces occupied by outpatients.

Given the differences between the users' necessities, it is common to see parking users stopping in areas not designated to park, which had considerably increased traffic congestion in recent years. To our knowledge, research about the efficient management of hospital parking facilities is limited. However, some studies assessed the topic, including Yu and Chan (2008), who describe a service model to integrate a parking guidance system (PGS) with patients' electronic health records. The proposed integrated system differentiates between healthcare users (emergency patients and healthcare providers who perform emergency operations). It would, among other functionalities, reserve a parking space and complete registration before the patient's arrival. Ali and Hassan (2019), Suthanaya (2017), and Alfadhlani and Afrinaldi (2019) found that parking demand was higher than the provided parking space at public and private hospitals in Indonesia and Malaysia. Guo simulated three hospital parking management strategies based on queuing theory. The findings support the view that automated parking systems can dismiss large hospitals' traffic congestion problems.

To assist in solving problems related to hospital parking capacity, researchers had suggested the implementation of SPS, which mitigates capacity problems without significantly increasing additional parking spaces (Alfadhlani and Afrinaldi, 2019; Ali and Hassan, 2019; Caicedo, 2010; Chen et al., 2017; Giuffre et al., 2012; Guo et al., 2018; Horng et al., 2012; Suthanaya, 2017). However, the SPS implementation might not be adequate for all parking lot facilities; the parking operation should consider the overall number of aisles and areas available in combination with the types and expected number of users. The number of users and location configuration might negatively affect the SPS advantages (Costa et al., 2014; Perković et al., 2020); therefore, designing a tool to support an SPS's adaptation becomes necessary for hospital facilities.

\section{Methods}

We propose the development of discrete simulation models using Rockwell Software Arena ${ }^{\circledR}$ to assess whether SPS has a beneficial effect on users' time searching for parking spaces. We evaluate the models by analyzing the following key variables: (i) number of aisles, (ii) number of slots per passage or corridor, and (iii) type of users. The aim is to establish the level at which it is advantageous to implement SPS technology in a parking lot. The research setting is a hospital and research center from Saudi Arabia (i.e., H\&RC-KSA); this is a 1589-bed care and referral hospital. H\&RCKSA is a center for oncology, organ transplantations, cardiac surgery, and genetic diseases.

The H\&RC-KSA parking administration plans to use an SPS system directly integrated with video smart link technology and sensors combined with a PARC structure that provides real-time data to reduce drivers' transfer time to find an available space. The proposed simulation model will assist in evaluating the most 
convenient parking locations to where implement SPS. The model estimates regular daily traffic and calculates the time spent by each user while finding their destination spot.

There are two available configurations of parking lots at the facility. The first lot is a building type (i.e., L-Building) with eight levels, each with the same capacity, three aisles, and fifty spaces per corridor (150 total spaces per floor). Figure 1 (a) showsa scaled map for anL-Building parking lot level. The second configuration is an open lot parking area (i.e., S-Open) with two main aisles and twenty spaces per passage (40 total spots) adjacent to the L-Building. Figure 1 (b) shows the aerial view of the SOpen parking lot.

(a)

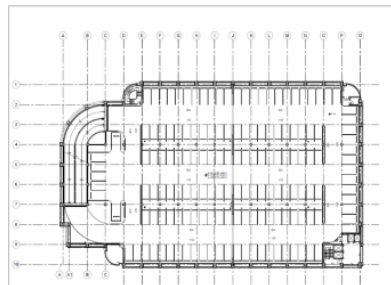

(b)

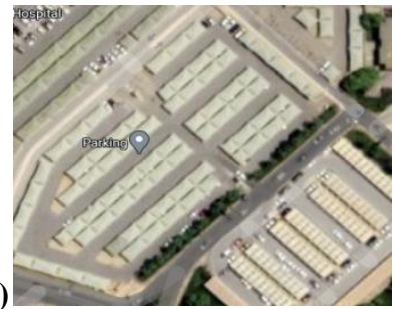

Figure 1 Blueprint for L-Building (a) and S-Open (b) Parking Lot, Retrieved from https://maps.google.com

Essential medical and administration staff have spots reserved in the L-Building. Other non-essential medical staff, emergency patients, outpatients, and visiting groups must park in either of the two parking locations. The purpose of the parking administration is to evaluate and optimize how traffic congestion affects users' time while looking for spaces on one floor of the L-Building and the S-Open parking lots. The parking administration requests to evaluate an L-Building level because it replicates the other building levels.

\subsection{SPS Simulation Model Logic}

We develop two models to assess the aspects of each parking configuration. We proceed to test two scenarios when there is no SPS technological assistance to find a parking spot (i.e., without-SPS), and then users will drive through the aisles until they find a space. In contrast, for the second scenario, the model provides technological support to the users by displaying the number of available spots per hall or corridor and communicating their best parking location (i.e., with-SPS). Figure 2 presents the simulation model logic to perform the evaluation.

The proposed scenario comparison evaluates whether the implementation of SPS will generate operational performance improvement in each parking configuration. The evaluation's primary performance metric is users' time while looking for available spaces in each parking lot (i.e., average transfer time). 


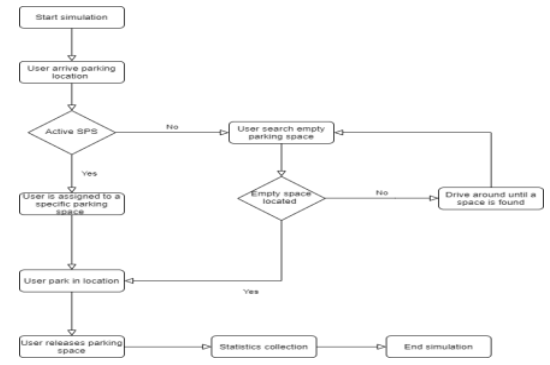

Figure 2 Simulation Model Logic

\subsubsection{L-Building Model}

The L-Building model simulates the operations of the parking area on a regular day of the hospital. In this parking configuration, the roads are two ways in each corridor of the floor with a maximum of $20 \mathrm{Km} / \mathrm{h}$ while driving for all users. Medical staff parking has a reserved area of parking, as described in Figure 3.

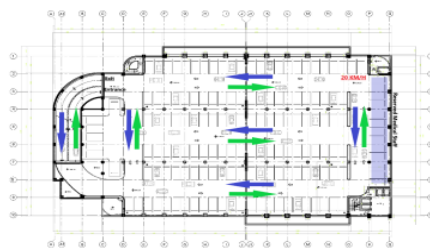

Figure 3 L-Building Model Layout

\subsubsection{S-Open Model}

For the S-Open model, the roads are two ways in each hall of the area with a maximum of $20 \mathrm{Km} / \mathrm{h}$ while driving for all users. There are no reserved spots for medical staff, and drivers can park in any open area of the layout as described in Figure 4.

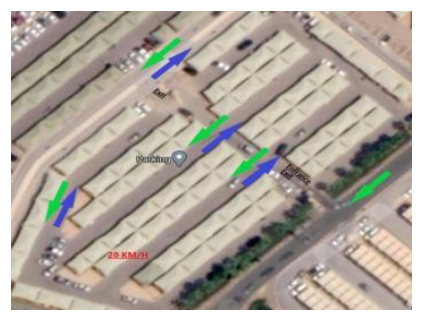

Figure 4 S-Open Model Layout

\subsection{SPS Simulation Parameters}

In the simulation, we estimate model parameters based on the hospital's historical data from 2017. The key parameters are the inter-arrival time between users, the number of parking spaces, system configuration, car speed, and total parking times. Table 1 shows the parameter probability distribution fitting using historical data for each parking configuration. 
Table 1 Parking Simulation Parameters

\begin{tabular}{|l|l|c|}
\hline \multicolumn{1}{|c|}{ Parameter } & \multicolumn{1}{c|}{ L-Building } & S-Open \\
\hline Cars inter-arrival time (mins) & EXPONENTIAL (0.8) & EXPONENTIAL (1.45) \\
\hline Parking time (hours) & TRIANGULAR $(1.1,2,2.4)$ & TRIANGULAR $(1.1,2,2.4)$ \\
\hline Number of spaces & 150 & 40 \\
\hline
\end{tabular}

The number of replications set for the models is $n=100$, and the replication length is 12 hours. Entities in the model are the drivers (users), and attributes for each follow the established probabilistic parameters. The global variable of interest is the average transfer time when drivers find a parking space.

\section{Parking Simulation Results}

We proceed to design and run the models using decision blocks to simulate the established logic. Each model considers the transfer time between spots per aisle using the speed restriction set by the hospital. The following sections describe the obtained results with graphical depictions of the simulation designing.

\subsection{L-Building Model Results}

Figure 5 shows the L-Building model (with 150 parking spaces capacity) and the Arena ${ }^{\circledR}$ simulation model's decision blocks.

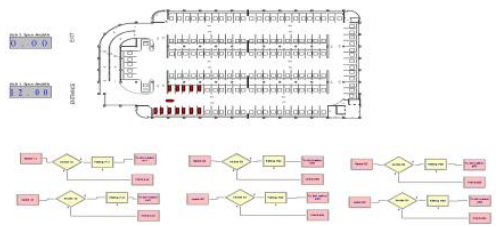

Figure 5 L-Building ARENA Simulation Model

After running the model, the with-SPS and the without-SPS scenarios are evaluated based on the variable average transfer time's performance. Figure 6 illustrates the performance comparison of both strategies. Ahypothesis test at a $95 \%$ confidence level confirms that the mean transfer time is significantly different ( $\mathrm{p}$-value $<0.0001)$ when SPS is available.

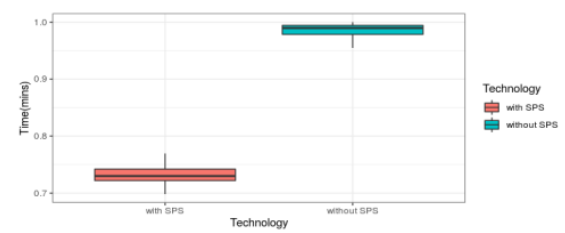

Figure 6 L-Building: with-SPS vs. without-SPS Time Comparison

\subsection{S-Open Model Results}

Figure 7 shows the S-Open model (with two aisles and 40 parking spaces in total) and the Arena ${ }^{\circledR}$ simulation model's decision blocks. 


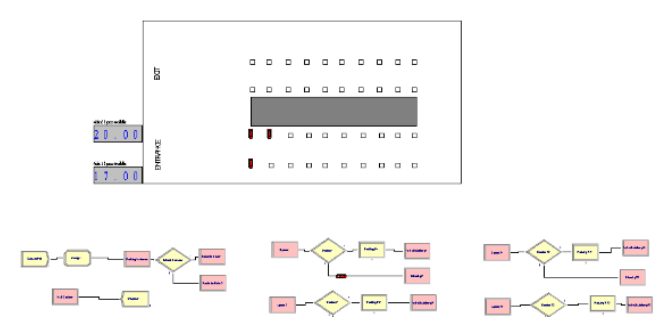

Figure 7 S-Open ARENA Simulation Model

Figure 8 illustrates the performance comparison of both scenarios. A $95 \%$ confidence hypothesis does not reject the hypothesis that the average transfer time is equal for with-SPS and without-SPS (p-value=0.015). The with-SPS strategy's average time is slightly higher than the without-SPS; this result differs significantly from the L-Building parking evaluation.

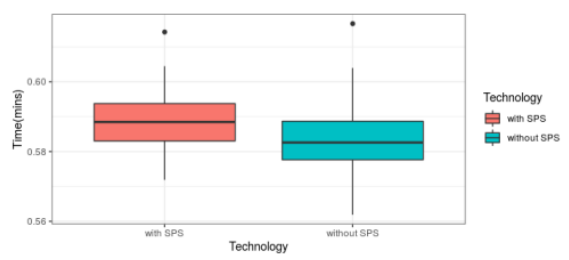

Figure 8 S-Open: with-SPS vs. without-SPS Time Comparison

\section{Discussion}

Hospital traffic congestion is a fundamental concern in large hospitals. Parking management strategies like SPS can mitigate these complications, allow patients to receive diagnosis and treatment on time, and provide medical staff and visitors a faster transfer time when on route to their final destinations. A review of previous studies indicated that few investigations had presented robust evidence that supports the use of information and communications technologies in different types of hospital parking facilities. In this research, we assess the impact of smart parking technologies on other hospital parking configurations. We modeled a hospital's parking operations using Rockwell Software Arena ${ }^{\circledR}$. We simulate the hospital parking facilities and evaluate the system by analyzing the parking operations with and without information and communication technologies.

This research indicates that drivers' transfer time improvements will depend on the parking configuration's various factors and aspects such as the car arrival rate, car flow, and parking visibility. In our study, the parking configuration showed to be relevant since as the number of aisles and spaces per aisle increases, SPS's implementation enhances drivers' time performance to find an available spot. In condensed parking areas, decision-makers should not take for granted that technology investments will improve operational performance. In some cases, it might even be detrimental to the overall operation, as presented in this study (see Figure 8). In larger size parking areas, communication technologies provided an edge for in-car flow time. A single level of the L-Building showed statistical significance in transfer times when SPS was available in contrast with the condensed parking lot analyzed (S-Open). This 
result suggests that if the building's size increases horizontally or vertically (multistory building), SPS technology's advantages will grow larger.

Besides the parking size and number of aisles, other factors that may impact implementing smart parking technologies are the car arrival rate, parking visibility, and cars' flow. The arrival rate refers to the exceeding of parking capacity. Parking with high capacity usage will be more likely to require SPS technologies (Lin et al., 2017). Parking visibility denotes drivers' possibility to visualize available parking spots either physically or technologically; in parking locations where walls or physical aspects limit user's visibility, SPS can help manage parking assignments (Paidi et al., 2018).Cars' flow refers to how cars move in the parking area and if they have the freedom to roam the parking (e.g., if parking roads are one way or two ways and elevators that transfer cars around the parking are available). These elements, combined with the parking layout, have a significant potential impact on SPS implementation's convenience.

\section{Conclusions}

In this study, the proposed discrete simulation models analyzed the impact of SPS in managing parking spaces, focusing on reducing the time spent searching for a parking spot. The models evaluate different parking configurations with a variable number of aisles, the number of spaces per hallway, and technologies available. We found that SPS will improve operational metrics in large-sized parking buildings with multiple corridors and halls. However, it might not enhance small-size parking lots with simple configurations or layouts.

Future research in parking management systems for healthcare facilities should also consider preference-based parking to prioritize spaces for physicians, medical workers, and critical patients. The number of users with limited mobility is potentially higher in a hospital parking lot than in other locations, highlighting that hospital service does not begin when patients arrive at the front desk. Still, it starts when patients access the parking area.

\section{Acknowledgments}

The work performed by Daniel Romero-Rodriguez has been partially supported by the Colombian Government through the COLCIENCIAS-scholarship CONV2015CC1129579108 and co-financed by the Universidad del Norte through the XVII ConvocatoriaInterna de Investigación UNINORTE. The Colombian Government has partially supported Julio-Mario Daza-Escorcia through the COLCIENCIASscholarship CONV-617-2013-CAP3-CC72357251. The work performed by Juan Pablo Escorcia-Caballero has been partially supported by the Colombian Government through the COLCIENCIAS-scholarship CONV-649-2014-CC1082839996 and cofinanced by the Universidad del Norte through the XVII ConvocatoriaInterna de Investigación UNINORTE.

\section{References}

1. Alam, M., Moroni, D., Pieri, G., Tampucci, M., Gomes, M., Fonseca, J., Ferreira, J., et al. (2018), "Real-time smart parking systems integration in distributed ITS for smart cities", Journal of Advanced Transportation. 
2. Alfadhlani, W. and Afrinaldi, F. (2019), "An evaluation on Dr. M. Djamil Hospital Padang parking lot capacity", IOP Conference Series: Materials Science and Engineering. IOP Publishing, p. 012038.

3. Ali, A. and Hassan, S. (2019), "Review of Malaysian current practice in supply/demand of parking in the hospital", IOP Conference Series: Materials Science and Engineering. IOP Publishing, p. 012057.

4. Caicedo, F. (2009), "The use of space availability information in 'PARC' systems to reduce search times in parking facilities", Transportation Research Part C: Emerging Technologies, Vol. 17 No. 1, pp. 56-68.

5. Caicedo, F. (2010), "Real-time parking information management to reduce search time, vehicle displacement and emissions", Transportation Research Parte D: Transport and Environment, Vol. 15 No. 4, pp. 228-234.

6. Chams-Anturi, O., Escorcia-Caballero, J.P., P. Gomez, A. and Soto-Ferrari, M. (2020), "Analysis of competitiveness in supply chain integration and logistics: An evidence from a public hospital network", Proceedings of the International Conference on Industrial Engineering and Operations Management, pp. 176-188.

7. Chen, Q., He, P. and Chen, J. (2017), "Analysis on time window of shared parking in hospitals based on parking behaviors", Discrete Dynamics in Nature and Society. Hindawi, pp. 1-11.

8. Costa, A., Rocha, C. and Melo, S. (2014), "Parking management policies and the effectiveness of public policy solutions", Procedia-Social and Behavioral Sciences, Vol. 111, pp. 965-973.

9. Ganesan, K. and Vignesh, K. (2007), “Automated parking slot allocation using RFID technology", IEEE 9th International Symposium on Signal Processing and Its Applications. IEEE, pp. 1-4.

10. Geng, F. and Cassandras, C. (2012), "A new 'Smart Parking' system infrastructure and implementation", 15th Meeting of EURO Working Group on Transportation, Elsevier Publications, Procedia - Social and Behavioral Sciences, Vol. 54, pp. $1278-1287$.

11. Giuffre, T., Siniscalchi, S. and Tesoriere, G. (2012), "A novel architecture of parking management for smart cities", Procedia: Social and Behavioral Science, Vol. 53, pp. 16-28.

12. Grazioli, A., Picone, M. and Zanichelli, M. (2013), "Collaborative mobile application and advanced services for smart parking", IEEE 14th International Conference on Mobile Data Management, pp. 39-44.

13. Guo, Y., Zhang, Y., Zhao, Y., Jia, Q., Jing, Z., Ren, Y., Li, R., et al. (2018), "Traffic congestion evaluation and management optimization based on queueing model and VISSIM simulation", IEEE 22nd International Conference on Computer Supported Cooperative Work in Design, pp. 672-676.

14. Haoui, A., Kavaler, R. and Varaiya, P. (2008), "Wireless magnetic sensors for traffic surveillance", Transportation Research Parte C: Emerging Technologies, Vol. 6 No. 3, pp. 294-306.

15. Horng, G., Wang, C. and Cheng, S. (2012), "Using cellular automata on recommendation mechanism for smart parking in vehicular environments", IEEE 2nd International Conference on Consumer Electronics, Communications and Networks. IEEE, pp. 3683-3686. 
16. Jermsurawong, J., Ahasan, U., Haidar, A., Dong, H. and Mavridis, N. (2014), "One-Day long statistical analysis of parking demand by using single-camera vacancy detection", Journal of Transportation Systems Engineering and Information Technology, Vol. 14 No. 2, pp. 33-44.

17. Klappenecker, A., Lee, H. and Welch, J. (2014), "Finding available parking spaces made easy", Ad Hoc Networks, Vol. 12, pp. 243-249.

18. Kotb, A., Shen, Y. and Huang, Y. (2017), "Smart parking guidance, monitoring and reservations: A review", IEEE Intelligent Transportation Systems Magazine, Vol. 9 No. 2, pp. 6-16.

19. Kuo, Y., Balasubramanian, H. and Chen, Y. (2020), "Medical appointment overbooking and optimal scheduling: Tradeoffs between schedule efficiency and accessibility to service", Flexible Services and Manufacturing Journal, Vol. 32 No. 1, pp. 72-101.

20. Lan, K. and Shih, W. (2014a), "An intelligent driver location system for smart parking”, Expert Systems with Applications, Vol. 41 No. 5, pp. 2443-2456.

21. Lan, K. and Shih, W. (2014b), "An intelligent driver location system for smart parking”, Expert Systems with Applications, Pages, Vol. 41 No. 5, pp. $2443-$ 2456.

22. Lin, T., Rivano, H. and Le Mouël, F. (2017), "A survey of smart parking solutions", IEEE Transactions on Intelligent Transportation Systems, Vol. 18 No. 12, pp. 3229-3253.

23. Paidi, V., Fleyeh, H., Håkansson, J. and Nyberg, R. (2018), "Smart parking sensors, technologies and applications for open parking lots: A review", IET Intelligent Transport Systems, Vol. 12 No. 8, pp. 735-741.

24. Perković, T., Šolić, P., Zargariasl, H., Čoko, D. and Rodrigues, J. (2020), "Smart parking sensors: State of the art and performance evaluation", Journal of Cleaner Production, Vol. 262, p. 121181.

25. Prasad, G., Sharath, U., Amith, B., Supritha, B., Asokan, S. and Hegde, G. (2013), "Fiber braggs grating sensor instrumentation for parking space occupancy management", International Conference on Optical Engineering, pp. 1-4.

26. Schäfer, F., Walther, M., Hübner, A. and Kuhn, H. (2019), "Operational patientbed assignment problem in large hospital settings including overflow and uncertainty management", Flexible Services and Manufacturing Journal, Vol. 31 No. 4, pp. 1012-1041.

27. Suthanaya, P. (2017), "Development of parking demand model for private hospital in developing country (case study of Denpasar City, Indonesia)", Journal of Sustainable Development, Vol. 10 No. 5, pp. 52-60.

28. Teodorovic, D. and Lucic, P. (2006), "Intelligent parking systems", European Journal of Operational Research, Vol. 175, pp. 1666-1681.

29. Xu, B., Wolfson, O., Yang, J., Stenneth, L., Yu, P. and Nelson, P. (2013), "Realtime Street Parking Availability Estimation", IEEE 14th International Conference on Mobile Data Management, pp. 16-25.

30. Yu, W. and Chan, M. (2008), "A service engineering approach to a mobile parking guidance system in uhealthcare", IEEE International Conference on E-Business Engineering, pp. 255-261. 
31. Zhu, D. (2018), "Deep learning over IoT big data-based ubiquitous parking guidance robot for parking near destination especially hospital", Personal and Ubiquitous Computing, Vol. 22, pp. 1109-1116.

\section{About Our Authors}

Milton Soto-Ferrari is an Assistant Professor in the Department of Marketing and Operations at Indiana State University. His research interests include business analytics, supply chain management, and logistics. His recent publications are related to data-driven decision-making, simulation applications, healthcare analytics, and industry forecasting policies.

Daniel Romero-Rodriguez is an Assistant Professor in the Industrial Engineering Department at Universidad del Norte in Barranquilla, Colombia. He completed a Ph.D. in Industrial Engineering at the University of South Florida. His research interests include Resilience Measurement, Social Systems Resilience, and Supply Chain Risk Management. He is a researcher of the project "Voluntarily redistribution of immigrants in Colombia" in collaboration with the Immigration Policy Lab from Stanford University.

Julio-Mario Daza-Escorcia is an Industrial Engineer graduated atCorporaciónUniversitaria de la Costa (CUC), with a Masters in Industrial Engineering at Universidad del Norte, Barranquilla, Colombia. He is an Assistant Professor in the Department of Industrial Engineering at Fundación Universidad de América (Colombia). His research interests are in combinatorial optimization and supply chain management.

Odette Chams-Anturi is an Assistant Professor at the Science Economics Department, Universidad de la Costa (Colombia). Her research interests are in Supply Chain Management, Organizational Learning, Innovation, and Ambidexterity. She has worked in public and private companies of mass consumption and healthcare entities. She has published articles in the Business Research Quarterly, Personnel Review, International Journal of Supply Chain Management, among others.

Juan P. Escorcia-Caballero is an Assistant Professor at the Entrepreneurship and Management Department, Business School, Universidad del Norte (Colombia). His research interests are Supply Chain Quality Management, Innovation, Ambidexterity, and Industry 4.0. He has published several journals and conference papers. He has participated in several research projects funded by the Administrative Department of Science, Technology, and Innovation of Colombia. He has published articles in the Total Quality Management \&Business Excellence, Personnel Review, Journal of Medical Systems, between others. 